\title{
Revision surgery for degenerative spinal deformity: a case report and review of the literature
}

\author{
Pasquale Donnarumma $^{1} \cdot$ Roberto Tarantino $^{1} \cdot$ Lorenzo Nigro $^{1} \cdot$ Maria Fragale $^{1} \cdot$ Roberto Bassani $^{2} \cdot$ \\ Roberto Delfini ${ }^{1}$
}

Received: 21 April 2017 / Revised: 31 August 2017 / Accepted: 4 September 2017

(C) International Spinal Cord Society 2017

\begin{abstract}
Introduction Management of spinal degenerative deformities always represents a challenge for the spinal surgeon.

Case presentation We report a case of revision surgery for adult scoliosis, focusing of most common errors in pre-surgical management and criteria for reoperation. We analyzed the spino-pelvic parameters on the standing whole-spine X-ray and the role of sagittal balance. To restore $45^{\circ}$ of lumbar lordosis, we performed a L3 Pedicle Subtraction Osteotomy (PSO), along with L2-L3 and L3-L4 eXtreme Lateral Interbody Fusion (XLIF).
\end{abstract}

Discussion In cases of adult scoliosis, careful preoperative planning is necessary in an attempt to avoid difficult, expensive, and high-risk additional procedures.

\section{Introduction}

Management of spinal degenerative deformities always represents a challenge for the spinal surgeon. A recent analysis from a large multicenter database shows an overall $17 \%$ reoperation rate for rigid fixations [1]. The need for reoperation may be minimized by carefully considering the sagittal spinal alignment, spino-pelvic parameters, termination of fixation, and type of surgical procedure. We present a case of implant failure and revision surgery, analyzing the most common errors in pre-surgical management and criteria for reoperation.

\section{Sagittal alignment analysis}

Sagittal spino-pelvic alignment is analyzed pre-operatively on standing whole-spine X-ray scan. Spino-pelvic parameters are measured as following: pelvic incidence (PI) is defined as the angle between the perpendicular to the sacral

Pasquale Donnarumma

dott.pasquale.donnarumma@gmail.com

1 Department of Neurosurgery, Sapienza University, Viale del Policlinico 115, 00161, Rome, Italy

2 IRCCS Galeazzi Orthopedic Institute, Via Riccardo Galeazzi, 4, 20161, Milan, Italy plate and the line connecting the midpoint of the sacral plate to the bi-coxo-femoral axis. The PI is a morphological parameter, considered as a constant, independent of the spatial orientation of the pelvis. Sacral slope (SS) corresponds to the angle between the sacral plate and the horizontal plane. The SS is a positional parameter, varying according to the pelvis positioning. Pelvic tilt (PT) is considered as the angle between the line connecting the midpoint of the sacral plate to the bi-coxo-femoral axis and the vertical plane. The PT is also a positional parameter and its algebraic sum with the SS corresponds to the PI $(\mathrm{PI}=\mathrm{SS}+$ PT). Lumbar lordosis (LL) is defined as the extension spinal segment above the sacral plate. Thus it is measured using the Cobb's method from the sacral plate to the upper endplate of the most incline vertebrae into the thoracolumbar junction zone (corresponding to the inflection point where the spine transitions from lordosis to kyphosis) [2].

\section{Case presentation}

This is a 66-year-old, normal weight female patient with history of 10 years low back pain (post-menopausal onset at 56). Past medical history was unremarkable and there was no history of adolescent scoliosis. Conservative treatment with physical therapy, NSAIDs, and steroids was unsuccessful. In November 2013 she presented for recent appearance of right sciatica (GRS-Graphic Rating Scale for 
Fig. 1 Sagittal MRI (a) and CT (b) scan documented L3-L4 and L4-L5 degenerative

spondylolisthesis and stenosis of the spinal canal

Fig. 2 Whole-spine X-Ray scan showing a $25^{\circ}$ left lumbar scoliosis (apex in L3), with a compensation $25^{\circ}$ right dorsal curve (apex in T8), a sagittal imbalance $(+13 \mathrm{~cm})$. PI: $90^{\circ}$, PT: $45^{\circ}$, and LL: $55^{\circ}$
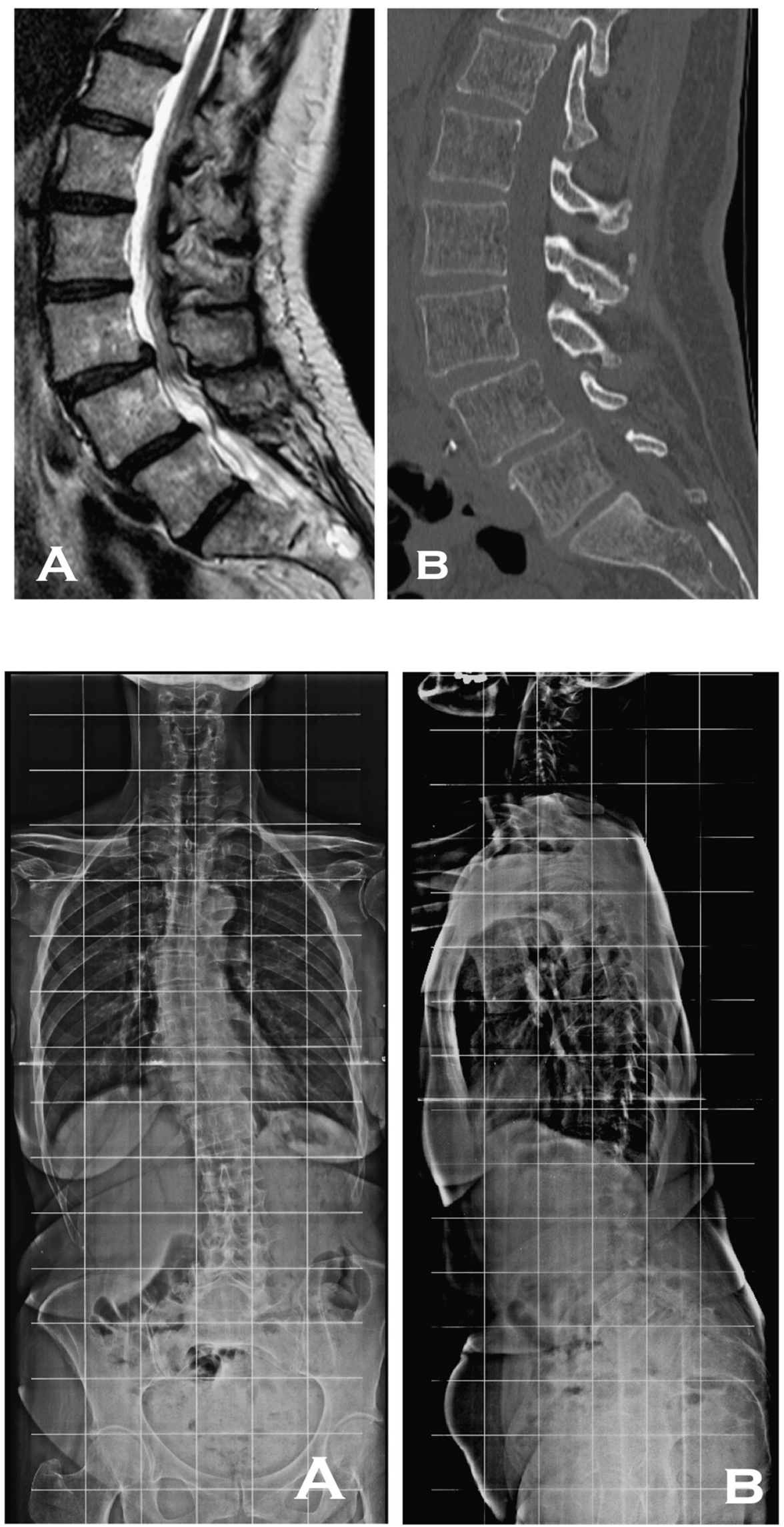
Fig. 3 Postoperative wholespine $\mathrm{X}$-ray showing an increase of sagittal imbalance $\left(+21.6^{\circ}\right)$, PI: $90^{\circ}$, PT: $41^{\circ}$ (Ideal PT: $26^{\circ}$ ), and LL: $35^{\circ}$
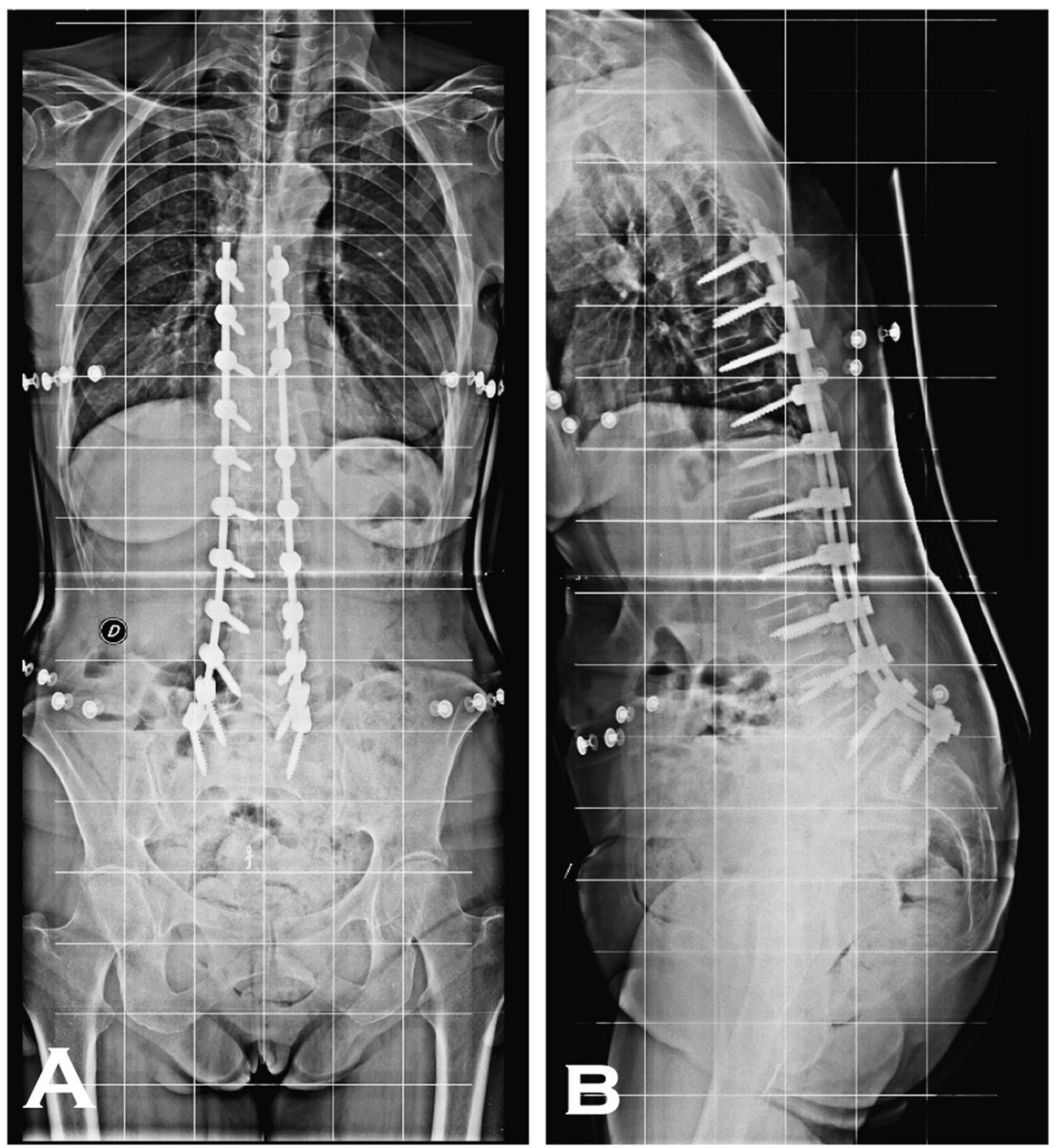

back-pain: 8, for right leg pain: 6). She had severe levels of disability (Oswestry Disability Index (ODI): 50\%) and low levels of quality of life (EQ5d EuroQuol VAS: 30\%). Lumbar MRI scan documented L3-L4 and L4-L5 degenerative stenosis and spondylolisthesis (Fig. 1). The standing whole-spine X-Ray showed a $25^{\circ}$ left lumbar scoliosis (apex in L3), with a compensatory $25^{\circ}$ right dorsal curve (apex in T8) and sagittal imbalance (C7-plumb line +13 $\mathrm{cm}$ ) (Fig. 2). The spino-pelvic parameters were the following: PI: $90^{\circ}$, PT: $45^{\circ}$, Ideal-PT: $26^{\circ}$ (according to the Vialle formula [3]), and LL: $55^{\circ}$. The initial surgical management consisted of L3-L4 posterior decompression and L4 nerve root decompression, T8-S1 pedicle screw fixation and coronal deformity correction.

Postoperative X-Ray scan showed a good correction of the coronal deformity $\left(\mathrm{Cobb}: 5^{\circ}\right)$ but an increase of sagittal imbalance (C7-plumb line: $+21,6^{\circ}$ ), PT: $41^{\circ}$ (Ideal-PT: $26^{\circ}$ ), and LL: $35^{\circ}$ (Fig. 3). 6 months after surgery the patient was referred to our clinic. Her level of disability was high (ODI: 83\%) and her quality of life very poor (Eq5d VAS: 10$)$. She had severe low back pain with no symptoms in her lower extremities (GRS: back-pain 9, legs-pain 0), trunk bent forward in standing position and ambulated only with crutches. The standing whole-spine X-Ray documented an increase of sagittal imbalance $(+25 \mathrm{~cm})$, PT: $45^{\circ}$, LL: $35^{\circ}$, an increase of the right dorsal curve (Cobb: $20^{\circ}$ ) and the pull out of the S1 screws (Fig. 4).

Revision surgery was performed in July 2014 consisting of: removal of the implanted rods, PSO (pedicle-subtraction-osteotomy) at L3, elongation of the implant at T2 with pedicle screws, repositioning of sacral screws and iliac screws, XLIF (eXtreme Lateral Interbody Fusion) at L2-L3 and L3-L4, and implant of lordotic titanium rods.

6 months after surgery the patient was able to walk independently. She presented low levels of back pain (GRS: 2 ), moderate levels of disability (ODI 32\%), and middle level of quality of life (EQ5D: 40). C7 plumb line $+3 \mathrm{~cm}$, PI: $90^{\circ}$, PT: $29^{\circ}$ (Ideal-PT: $26^{\circ}$ ), and LL: $60^{\circ}$ (Fig. 5). 
Fig. 46 months after surgery whole-spine X-ray showing an increase of sagittal imbalance $(+25 \mathrm{~cm}), \mathrm{PI}: 90^{\circ}, \mathrm{PT}: 45^{\circ}$, and LL: $35^{\circ}$, an increase of the right dorsal curve (Cobb: $20^{\circ}$ ) and the pull out of the screws on S1
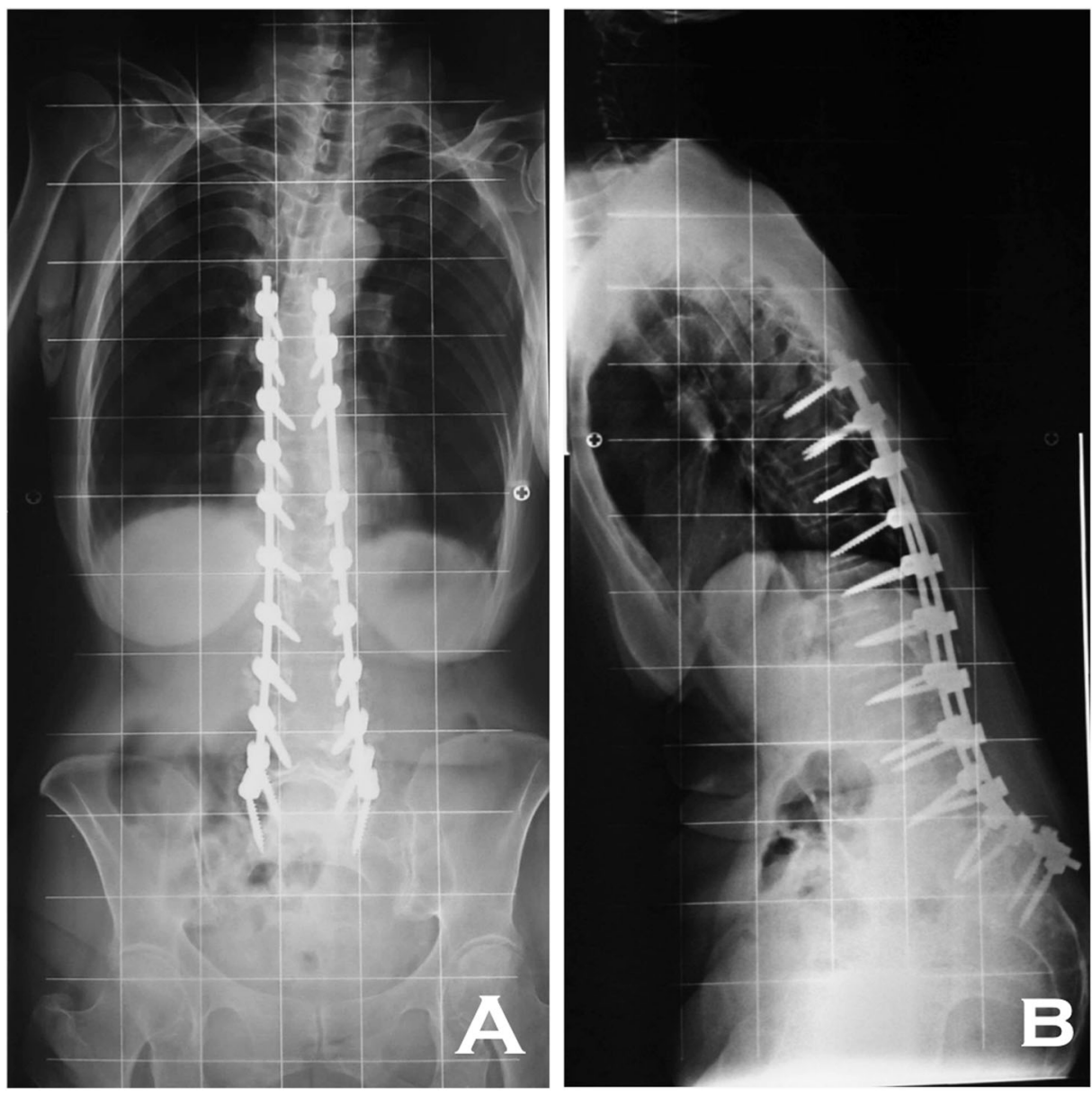

\section{Discussion}

According to Aebi classification of adult scoliosis [4], the patient presented a type 1 or primary degenerative scoliosis ("de novo" scoliosis). The first clinical manifestations of the deformity, mainly back pain, appeared during adulthood 2 years after the menopause and progressed with radicular pain and claudication. The post-menopause onset and the development of lumbar spine stenosis with radicular compression are typically encountered in type 1 scoliosis [4]. Although most patients with adult scoliosis are older and have significant comorbidities, evidence suggests that scoliosis independently and substantially burdens the health of the affected patients [5]. Unfortunately, common non-operative treatments do not change the quality of life of these patients [6]. Data from multicenter spinal deformity databases demonstrate the potential benefits of surgical treatment for adult scoliosis and suggest that the elderly, despite facing the greatest risk of complications, may stand to gain a disproportionately greater improvement in disability and pain with surgery [6]. Complications seem to be less common in patients between 66 and 74 , compared to those over 75 years [7]. Moreover, multiple comorbidities and the high risk of perioperative complications must be carefully considered before indicating surgery.

In our case the patient was a 66-year-old, normal weight female, with no comorbidities. At the first operation, the surgeons aimed to treat the lumbar spinal stenosis, the radicular compression, and the coronal deformities. Therefore, no analysis of spino-pelvic parameters was conducted. A severe sagittal imbalance $(\mathrm{C} 7$ plumb line $+13 \mathrm{~cm})$ with complete saturation of all physiological compensation mechanisms including hypolordosis, pelvic retroversion, thoracic spine hypokyphosis, and knee flexion were already present [2]. Although the patient did not present radicular pain 6 months after the first operation, she had severe thoracolumbar back pain and a complete loss of sagittal balance. She was also unable to walk and perform activities of daily living. These findings motivated revision surgery and sagittal balance restoring [8].

The role of sagittal (rather than coronal) deformities had been already recognized as crucial in the pathophysiology of low back pain [4, 9]. 
Fig. 5 Whole-spine X-ray after reoperation: good sagittal balance $+3 \mathrm{~cm}$, PI: $90^{\circ}$, PT: $29^{\circ}$ (Ideal PT: $26^{\circ}$ ), and LL: $60^{\circ}$
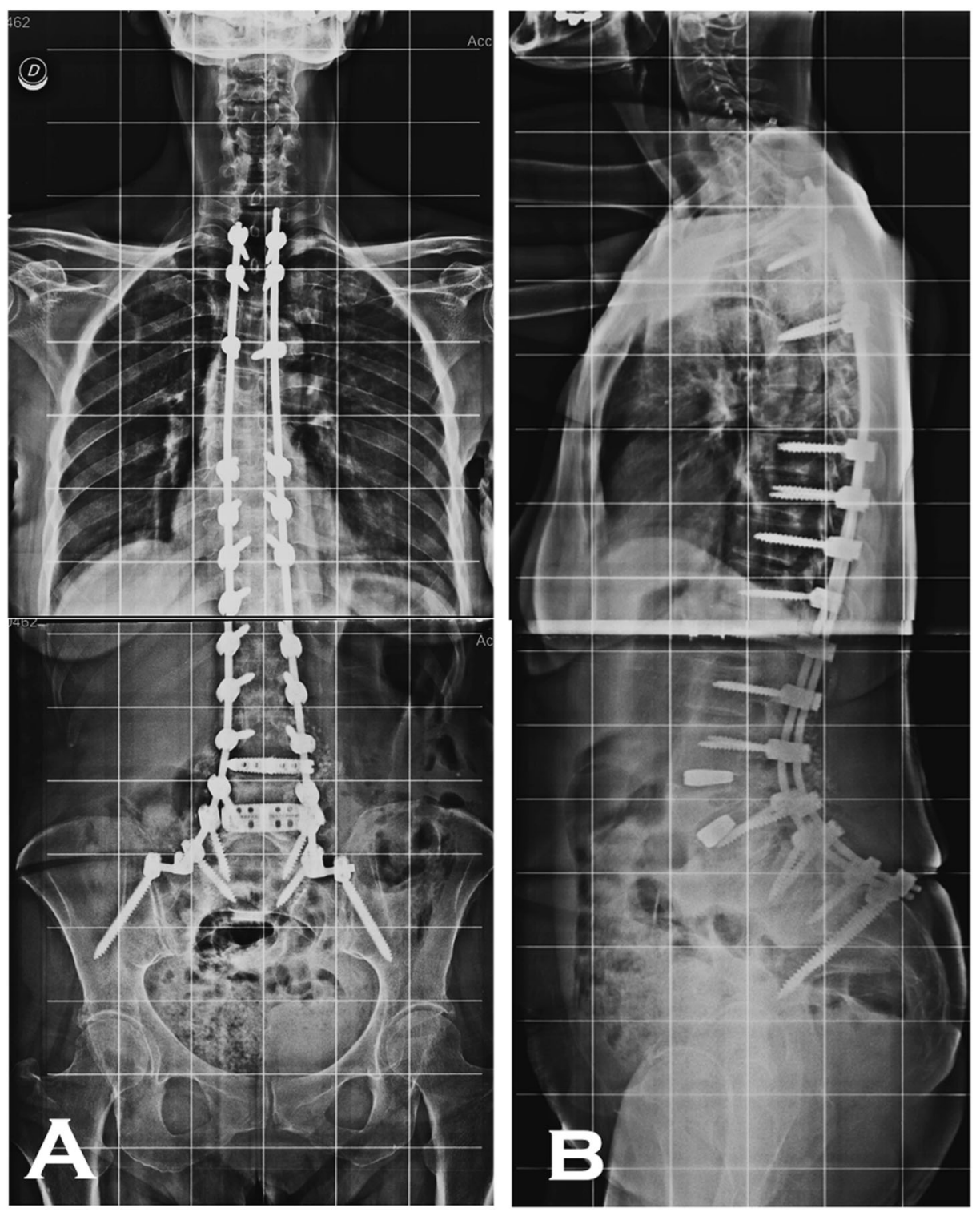

In this specific case, the sagittal balance should have been restored with a correction of about $35+10$ degrees of LL [10] at first surgery. The goal should be a short fixation, extending from T10 (proximal end-vertebra) [11] to the pelvis, and considering the option of lordotic cages in L2L3, L3-4, and L4-L5. Moreover, to start the fixation at T8 level is considered as an error, as T8 vertebra represent the counter curve apex. Proximal instrumentation should never stop at the apex of a curve to prevent curve progression and junction syndrome. In this case we observed, in fact, a proximal curve progression from $5^{\circ}$ to $20^{\circ}$ ( 6 months after surgery).

At second surgery, we performed PSO at L3, allowing 30 degrees of LL correction [12], along with XLIF at L2-L3 and L3-L4, allowing additional $10^{\circ}$ of correction. Interbody fusion was also performed in an effort to minimize the risk of implant failure resulting from L3 overload. Since studies have documented rod fracture in PSO settings where disk spaces were preserved above or adjacent to the PSO [5], placement of interbody cages in PSO settings has a potential stabilizing effect [10]. Since the thoracic counter curve progressed from $5^{\circ}$ to $20^{\circ}$, it required full fixation extending the instrumentation to $\mathrm{T} 2$ (counter curve proximal endvertebra).

\section{Conclusion}

Long instrumented spinal fusions involving the lumbosacral junction are exposed to implant problems [13] such as the 
pull-out of S1 screws which happened to our patient: a complication probably triggered/favored by an incomplete/ insufficient restoration of sagittal balance that required replacement with higher caliber screws along with the insertion of iliac screws to ensure fixation across the lumbosacral junction [14]. Nonunion at L5-S1 continue to be a problem to spine surgeons. Pseudarthrosis rates are reportedly $10 \%$ for an L5-S1 fusions, up to $20 \%$ for two-level fusions, and up to $72 \%$ for a long construct for adult spinal deformity that extends to the sacrum [15]. Long fixation ending at the sacrum, consisting in S1 pedicle screws and/or sacral alar screws alone, has demonstrated especially high failure rates [16, 17]. Alternatively, bilateral iliac screws coupled with bilateral S1 screws provide excellent distal fixation for lumbosacral fusions with a high fusion rate [8]. In cases of adult scoliosis, careful preoperative planning is necessary in an attempt to avoid difficult, expensive, and high-risk additional procedures [18, 19].

\section{Compliance with ethical standards}

Conflict of interest The authors declare that they have no competing interests.

\section{References}

1. Scheer JK, Tang JA, Smith JS, Klineberg E, Hart RA, Mundis GM, Jr. et al. Reoperation rates and impact on outcome in a large, prospective, multicenter, adult spinal deformity database: clinical article. J Neurosurg Spine. 2013;19:464-70. doi:https://doi.org/ 10.3171/2013.7.SPINE12901. Epub 23 Aug 2013.

2. Berjano P, Bassani R, Casero G, Sinigaglia A, Cecchinato R, Lamartina C. Failures and revisions in surgery for sagittal imbalance: analysis of factors influencing failure. Eur Spine J. 2013;22:S853-8. doi:https://doi.org/10.1007/s00586-013-3024-x. Epub 24 Sep 2013.

3. Vialle R, Levassor N, Rillardon L, Templier A, Skalli W, Guigui P. Radiographic analysis of the sagittal alignment and balance of the spine in asymptomatic subjects. J Bone Joint Surg Am. 2005;87:260-7.

4. Aebi M. The adult scoliosis. Eur Spine J. 2005;14:925-948. doi: https://doi.org/10.1007/s00586-005-1053-9.

5. Smith JS, Shaffrey CI, Ames CP, Demakakos J, Fu KM, Keshavarzi S. et al. International Spine Study Group. Assessment of symptomatic rod fracture after posterior instrumented fusion for adult spinal deformity. Neurosurgery. 2012;71:862-7.

6. Pellisé F, Vila-Casademunt A, Ferrer M, Domingo-Sàbat M, Bagó J, Pérez-Grueso FJ. et al. European Spine Study Group, ESSG. Impact on health related quality of life of adult spinal deformity (ASD) compared with other chronic conditions. Eur Spine J. 2015;24:3-11. doi:https://doi.org/10.1007/s00586-014-3542-1.
7. Bridwell KH, Glassman S, Horton W, Shaffrey C, Schwab F, Zebala LP. et al. Does treatment (nonoperative and operative) improve the two-year quality of life in patients with adult symptomatic lumbar scoliosis: a prospective multicenter evidencebased medicine study. Spine (Phila Pa 1976). 2009;34:2171-8. doi:https://doi.org/10.1097/BRS.0b013e3181a8fdc8.

8. Berjano P, Langella F, Ismael MF, Damilano M, Scopetta S, Lamartina C. Successful correction of sagittal imbalance can be calculated on the basis of pelvic incidence and age. Eur Spine J. 2014;23:587-96. doi:https://doi.org/10.1007/s00586-014-3556-8.

9. Chaléat-Valayer E, Mac-Thiong J-M, Paquet J, Berthonnaud E, Siani F, Roussouly P. Sagittal spino-pelvic alignment in chronic low back pain. Eur Spine J. 2011;20:634-40. doi:https://doi.org/ 10.1007/s00586-011-1931-2.

10. Deviren V, Tang JA, Scheer JK, Buckley JM, Pekmezci M, McClellan RT. et al. Construct rigidity after fatigue loading in pedicle subtraction osteotomy with or without adjacent interbody structural cages. Global Spine J. 2012;2:213-20. doi:https://doi. org/10.1055/s-0032-1331460.

11. Hey HWD, Tan KA, Neo CS, Lau ET, Choong DA, Lau LL. et al. T9 versus T10 as the upper instrumented vertebra for correction of adult deformity-rationale and recommendations. Spine J. 2017;17:615-21. doi:https://doi.org/10.1016/j.spinee.2016.11. 008 .

12. Youssef JA, Orndorff DO, Patty CA, Scott MA, Price HL, Hamlin LF. et al. Current status of adult spinal deformity. Global Spine J. 2013;3:51-62. doi:https://doi.org/10.1055/s-0032-1326950. Epub 5 Oct 2012.

13. Harimaya K, Mishiro T, Lenke LG, Bridwell KH, Koester LA, Sides BA. Etiology and revision surgical strategies in failed lumbosacral fixation of adult spinal deformity constructs. Spine. 2011;36:1701-10. doi:https://doi.org/10.1097/BRS. 0b013e3182257eaf.

14. Bradford DS, Tay BK, Hu SS. Adult scoliosis: surgical indications, operative management, complications, and outcomes. Spine. 1999;24:2617-29.

15. Kim YJ, Bridwell KH, Lenke LG. Pseudarthrosis in long adult spinal deformity instrumentation and fusion to the sacrum: prevalence and risk factor analysis of 144 cases. Spine. 2006;31:2329-36.

16. Kasten MD, Rao LA, Priest B. Long-term results of iliac wing fixation below extensive fusions in ambulatory adult patients with spinal disorders. J Spinal Disord Tech. 2010;23:e37-42. doi: https://doi.org/10.1097/BSD.0b013e3181cc8e7f.

17. Kuklo TR, Bridwell KH, Lewis SJ, Baldus C, Blanke K, Iffrig TM. et al. Minimum 2-year analysis of sacropelvic fixation and L5-S1 fusion using S1 and iliac screws. Spine (Phila Pa 1976). 2001;26:1976-83

18. Smith JS, Shaffrey CI, Glassman SD, Berven SH, Schwab FJ, Hamill CL. et al. Spinal Deformity Study Group. Risk-benefit assessment of surgery for adult scoliosis: an analysis based on patient age. Spine (Phila Pa 1976). 2011;36:817-24. doi:https:// doi.org/10.1097/BRS.0b013e3181e21783.

19. Drazin D, Al-Khouja L, Lagman C, Ugiliweneza B, Shweikeh F, Johnson JP. et al. Scoliosis surgery in the elderly: complications, readmissions, reoperations and mortality. J Clin Neurosci. 2016;34:158-61. doi:https://doi.org/10.1016/j.jocn.2016.06.005. 